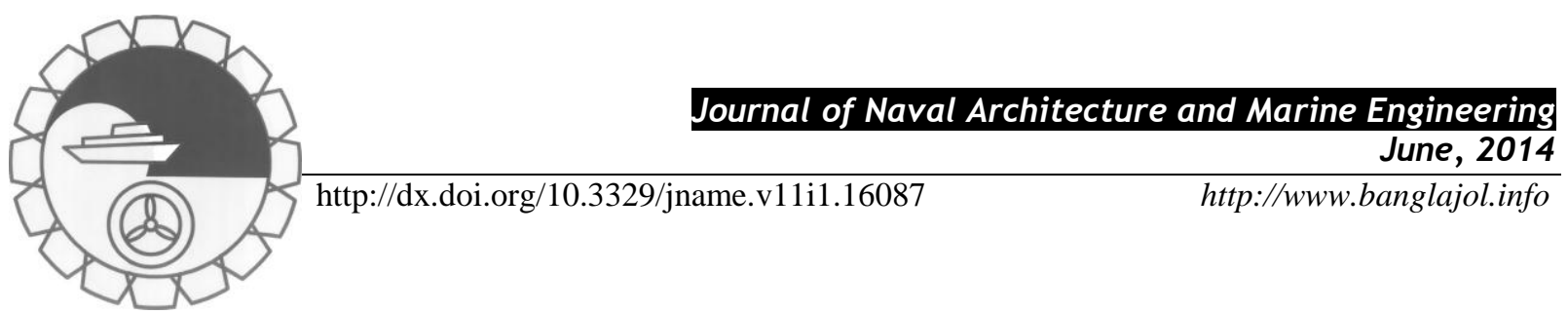

\title{
BUCKLING BEHAVIOUR OF UNDERWATER VESSELS BY EXPERIMENTAL, NUMERICAL AND ANALYTICAL APPROACHES
}

Moorthy, G. ${ }^{1}$, Narasimha Murthy, H.N.*¹, ShivKumar, Patil ${ }^{1}$, Sudarsan, K. ${ }^{2}$, Nandagopan, O.R. ${ }^{2}$, Ajith Kumar, K. ${ }^{2}$ and Krishna, M. ${ }^{1}$

${ }^{1}$ Department of Mechanical Engineering, R.V.College of Engineering, Bangalore, India E-mail: hnmdatta@ yahoo.com ${ }^{2}$ Scientist, Naval Physical and Oceanographic Laboratory, Cochin, India

\begin{abstract}
:
This paper reports the buckling behaviour of glass/vinylester polymer composite filament wound shells of underwater vessels. The shells were tested for buckling under hydrostatic loading and the corresponding strains were experimentally measured using strain gauges. Numerical analysis was performed for critical buckling pressure, stresses and strains using ANSYS. Von-Mises stresses corresponding to hydrostatic pressures were computed analytically. The numerical results of critical buckling pressure for $10 \mathrm{~mm}$ thick vessels showed $7.12 \%$ deviation from those of the experimental results because of the imposed boundary conditions, possibility of multiple configurations of the shell to deform around the buckling load and not accounting for initial imperfections in the shell in the Finite Element Analysis. The microstrains predicted by FEA were in good agreement with the experimental strains before the onset of buckling. Von-Mises stresses predicted by FEA agreed well with those of the analytical computations.
\end{abstract}

Keywords: Critical buckling pressure, FEA, reduced stiffness matrix, filament winding

\section{Introduction}

Underwater vessels suffer from buckling due to hydrostatic pressure which reduces their load carrying capacity. Research on buckling of shells has been carried out over many years with particular attention to isotropic materials. Application of polymer composites for underwater vehicle structures can reduce their weight and expand the depth of operation. Materials for underwater vessels must not only be capable of withstanding very high external pressures, but also have other properties such as good resistance to corrosion as these vessels are operated at both shallow and deep sea conditions, high strength to weight ratio, good sound absorption qualities, formability, operating life span of the material and the like. Advantage of using fibre-reinforced composites over conventional materials is that they can be tailored to the requirements.

Polymer composites for underwater vessels have been examined in the recent research. Ross (2006) proposed glass/polyester for underwater vessels based on the influence of operating environment and material properties on their structural stability. Smith (1991) identified the areas of uncertainties in the behaviour of polymer composites including failure criterion when subjected to compressive stresses. Joung et al. (2004) performed numerical analysis of underwater vessels made of polymer composites. Generally, cylindrical structures subjected to hydrostatic pressure undergo reduction in their structural stiffness and hence show high deformation at the onset of buckling which is termed as unstable buckling. In such structures buckling directly leads to structural or partial failure. Therefore, buckling is considered as a critical design condition for the structure (Hur et al., 2008).

Carvelli et al. (2001) recommended a procedure for numerical buckling analysis of underwater vessels based on experimental studies under deep sea environment of a complete vehicle composed of cylindrical, conical and hemispherical components. The authors suggested consideration of mainly cylindrical shells for predicting critical buckling pressure by numerical analysis as they form the weakest part. Winding angle and sequence influence buckling of filament wound cylindrical structures, Morenoa et al. (2008). Massager et al. (2002) optimized buckling capacity of thin cylindrical vessels using Genetic Algorithm and recommended $\pm 55^{\circ}$ orientation based on the studies considering $30^{\circ}, 45^{\circ}, 60^{\circ}, 75^{\circ}, 90^{\circ}$ orientations for polymer composites. Moreno et al. (2008) related the mechanical strength of filament wound vessels to the winding pattern of glass/epoxy cylinders exposed to external pressure and series of implosion tests were carried out in a hyperbaric 
chamber on cylindrical specimens of two pattern sizes and two wall thicknesses, made of continuous glass roving and epoxy resin.

Messager (2001) developed an analytical buckling model for laminated cylinder subjected to external pressure by taking into account third order shear deformation theory and linear buckling theory. The model overestimated the buckling pressure but provides good sensitivity to lamination pattern. The analytical results were correlated with those of experimental and numerical analyses.

Ross et al. (2008) reported experimental investigations of buckling characteristics of circular conical vessels made of isotropic material. The vessels tested under external hydrostatic pressure failed by plastic nonsymmetric bifurcation buckling or shell instability. Hur et al. (2008) simulated buckling phenomenon of moderately thick-walled filament-wound carbon/epoxy composite cylinders under external hydrostatic pressure for underwater vessels. All the analyses and tests proved that the cylinders collapsed after buckling as they did not recover initial pressure. Major failure modes in the tests were related to helical winding angles.

Review of literature on the buckling behaviour of polymer composite underwater vessels indicated that studies adopting static buckling and validation of experimental results with numerical and analytical approaches are scare. The main objective of this research was to examine the buckling performance of $10 \mathrm{~mm}$ and $15 \mathrm{~mm}$ thick glass/vinylester filament wound shells of underwater vessels subjected to hydrostatic loading by experimental, numerical and analytical approaches. The dimensions of the shell were selected based on a working model of underwater vessel employed for undersea explorations. Response of the shell under static pressure and critical buckling pressure based on Block Lancoz method was studied. Von-Mises stresses corresponding to applied pressure were computed analytically based on the experimental microstrains by Reduced Stiffness Matrix method.

\section{Experiment}

\subsection{Filament winding}

Glass fibres of $360 \mathrm{GSM}$ and vinylester composite shells of $825 \mathrm{~mm}$ length, $175 \mathrm{~mm}$ internal diameter and 10 $\mathrm{mm}$ and $15 \mathrm{~mm}$ thickness were fabricated using filament winding at M/s Uniglass Industries Pvt Ltd, Bangalore. Optimised winding angle of $\pm 55^{0}$ were used as per Massager et al. (2002), for which hoop stress was reported twice the axial stress. Vinylester resin with Di Methyl Acetamide as promoter, Cobalt napthalate as accelerator, Methly Ethyl ketone peroxide as catalyst in the proportion 100:2:2:2 respectively were used for the specimens. Vinylester was used as matrix resin based on its superior chemical resistance in sea ambience. The cylindrical specimens and strain gauge positions are shown in Fig. 1.
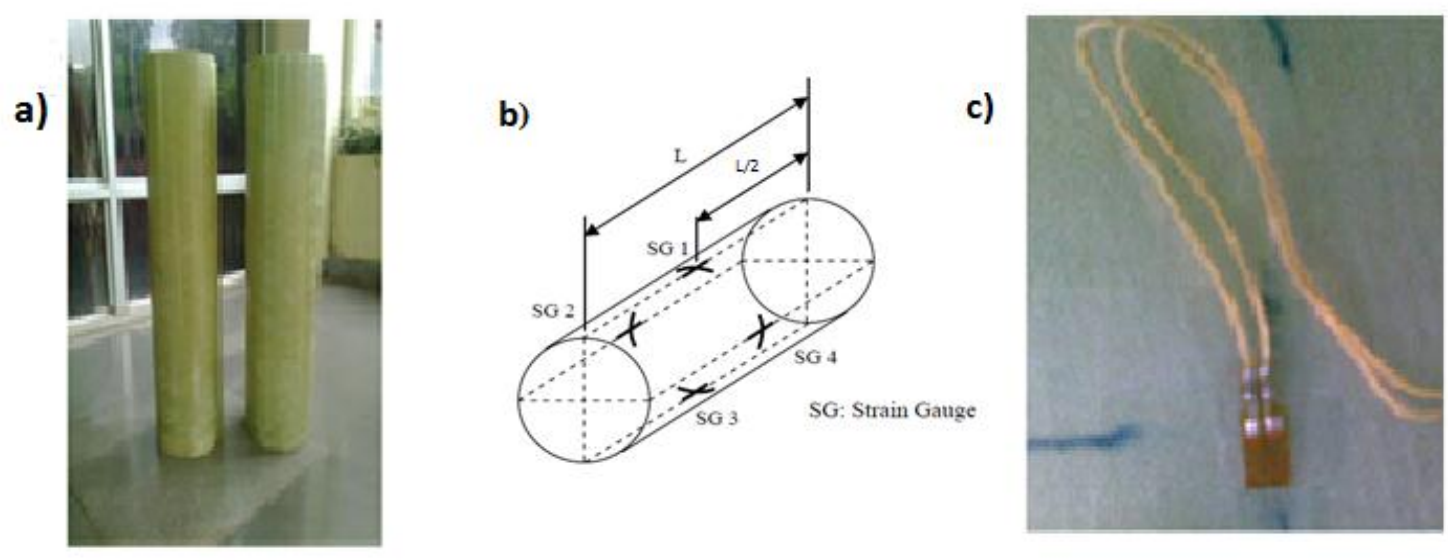

Fig. 1: a) Filament wound shells, b) Strain gauge positions, c) Strain gauge with cables

\subsection{Strain measurement}

Four strain gauges (M/s Tokyo Sokki Kenkyujo Co. Ltd) in circumferential direction at $0^{\circ}, 90^{\circ}, 180^{\circ}$ and $270^{\circ}$ and two strain gauges in longitudinal direction at $126^{\circ}$ and $162^{\circ}$ were mounted on the inner side at mid-length of the shells. The strain gauges were wired in a three cable configuration for connection to the strain indicator. The 
strain gauges were of resistance $350 \mathrm{ohm}$, length $5 \mathrm{~mm}$ and accuracy of gauge factor $\pm 0.3 \mathrm{ohm}$ (Fig. 2). A high precision, laboratory type digital display strain indicator (3800) was employed for strain measurement (Fig. 2). It features extremely wide range gage factor, balance, and bridge excitation controls. The resolution of the indicator was $0.1 \mu$.

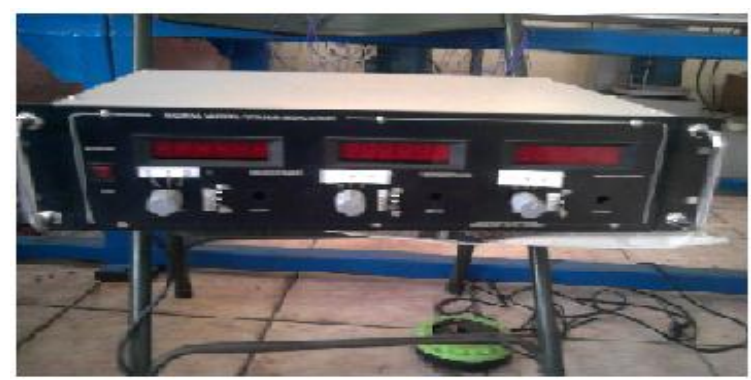

Fig. 2: Strain indicator

\subsection{Assembling filament wound shell with flanges using polyurethane rubber}

Polyurethane (PU) rubber was used as a seal between the cylinder and the flange to prevent oil leakage. The PU rubber was machined to suit the thickness of the shell. Fig. 3 shows the front and rear flange fixtures. Fig. 4 shows PU rubber and shell with flanges.

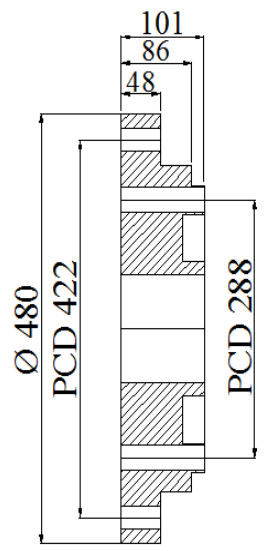

a)

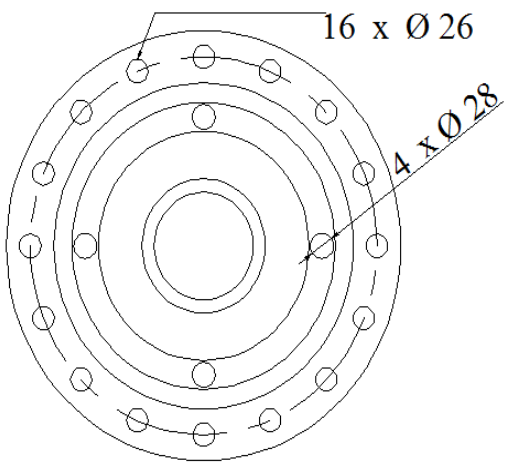

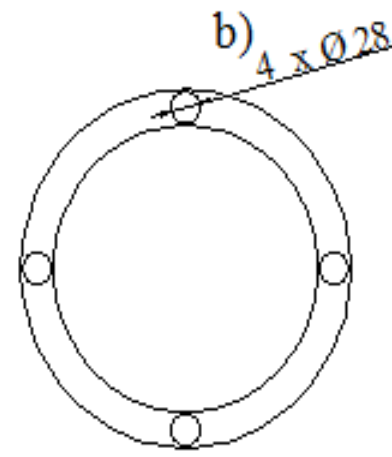

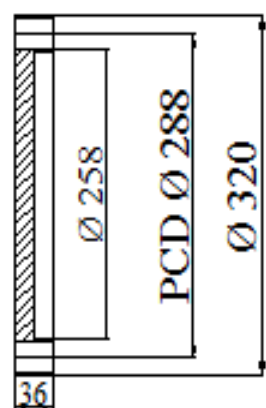

Fig. 3: a) Front flange fixture and b) Rear flange fixture
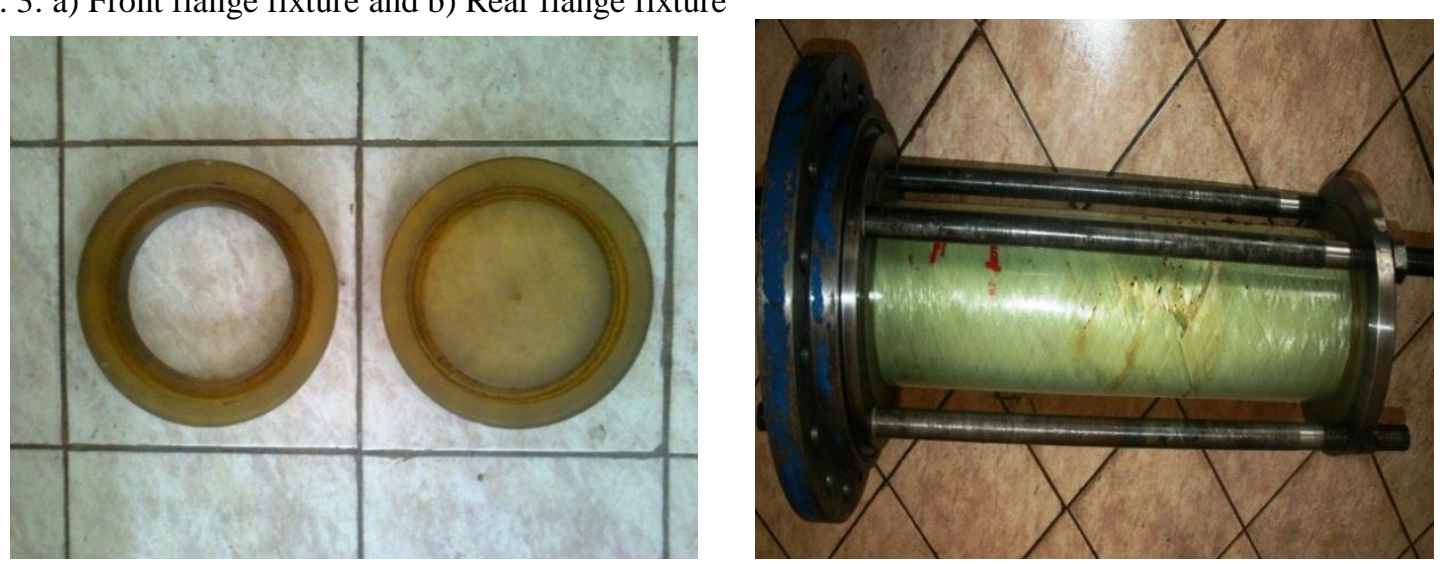

Fig. 4: a) PU rubber as oil seal, and b) Filament wound shell with flanges and PU rubber

\subsection{Testing of shells for buckling}

A custom designed buckling tester (Fig. 5) was used to apply hydrostatic pressure on the shells. Initially, oil is pumped from the oil drum to the buckling chamber. Once the buckling chamber is filled with oil, it overflows to 
the oil reservoir. Outlet valve of the buckling chamber and the inlet valve of the pump are closed. Pressure in the chamber is increased by supplying oil from the power pack. Strains corresponding to the applied pressures are recorded.

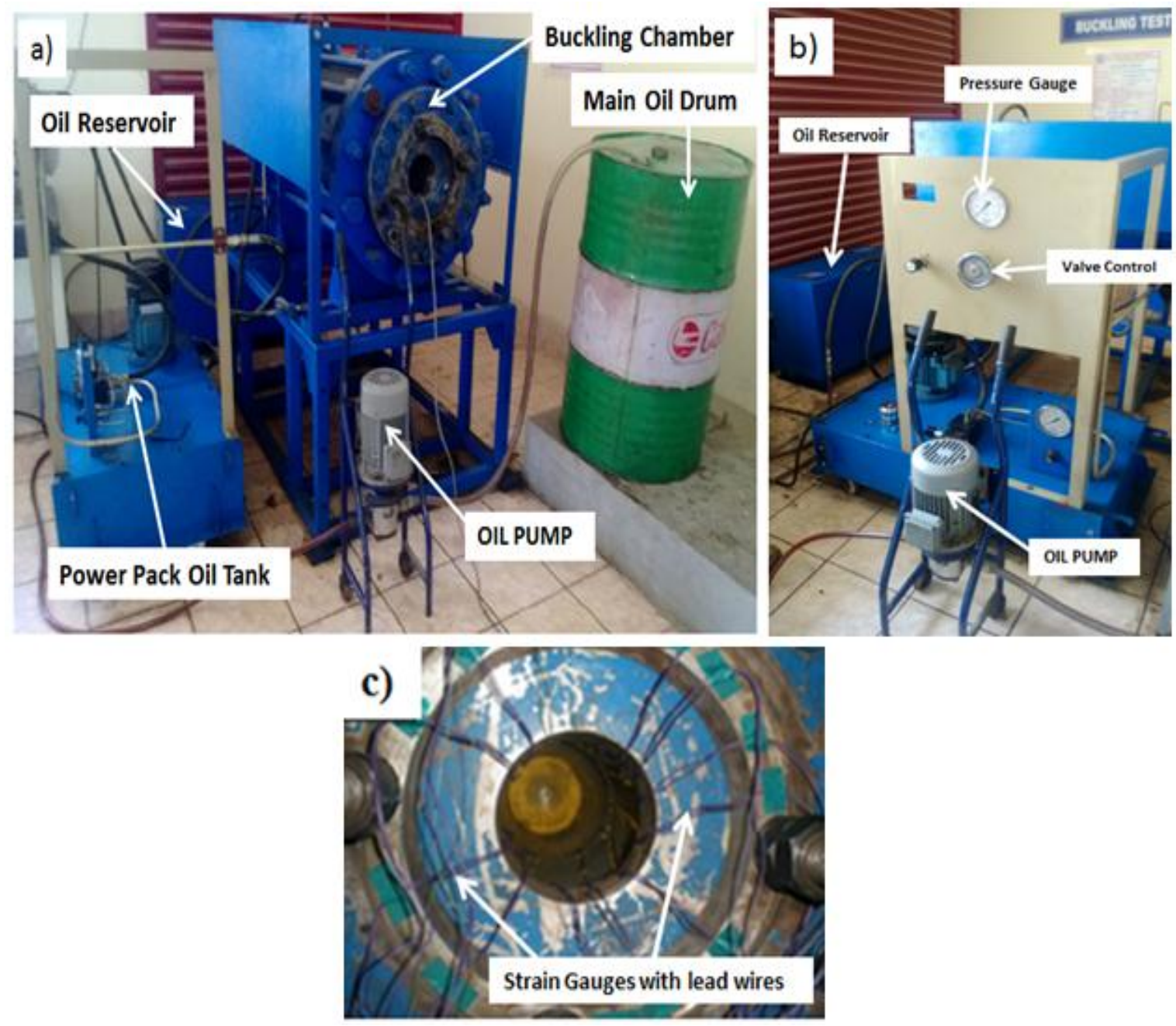

Fig. 5 a) Buckling Test Rig b) controls and gauges c) strain gauges and lead wires

\subsection{Experimental results}

The circumferential and longitudinal strain responses of $10 \mathrm{~mm}$ thick shell are shown in Table 1. Strains were used to determine the circumferential wave pattern of the shells. The strains were linear before the onset of buckling and changed suddenly around the buckling pressure as shown in Fig. 6. Compressive strains in circumferential direction were larger than those in the longitudinal direction. The magnitudes of the circumferential strains (Fig. 7) grew with increasing external pressure, eventually making a distinct wave pattern prior to collapse. Average of the four circumferential strains as a function of applied pressure is shown in Fig. 8. The shell experiences buckling due to hydrostatic pressure and hence fails. In polymer matrix composites the shells delaminate (Fig. 9) at the onset of buckling. In general, a cylinder-type structure under external pressure loses its structural stiffness and shows a large amount of deformation and hence high circumferential strain at the buckling point. The pressure-deformation curve showed a sharp drop after buckling which is termed as unstable buckling. It directly leads to structural or partial failure. Therefore, buckling is considered as a critical design condition for the structure. As buckling is the dominant failure criterion in shells subjected to hydrostatic pressure, its failure is characterized in terms of large circumferential strain.

Pressure-strain response was studied during loading and unloading of the shells of $15 \mathrm{~mm}$ thickness. The loading was limited to $16 \mathrm{MPa}$ due the limitation of range of pressure in the tester. The circumferential and longitudinal strain responses are shown in Table 2 (Loading) and Table 3 (Unloading). 
Table 1: Strain responses for $10 \mathrm{~mm}$ thick cylinder

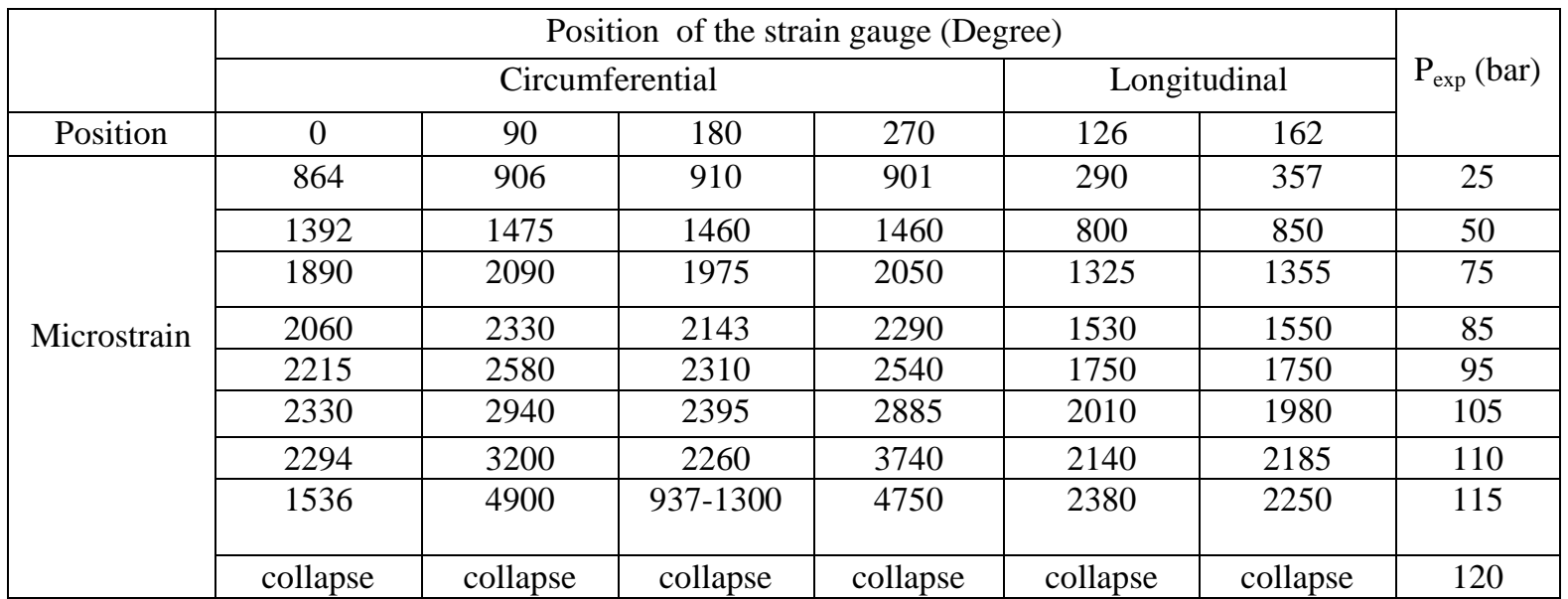

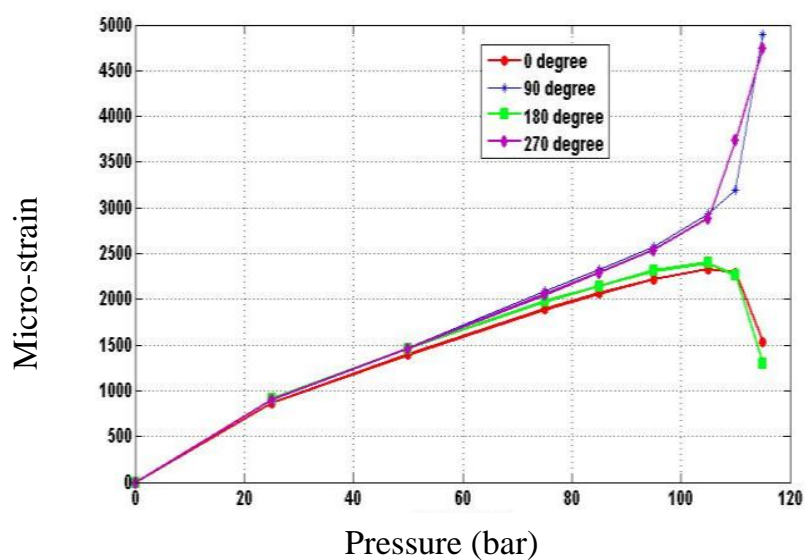

Fig. 6: Circumferential strains for $10 \mathrm{~mm}$ thick vessel at different locations

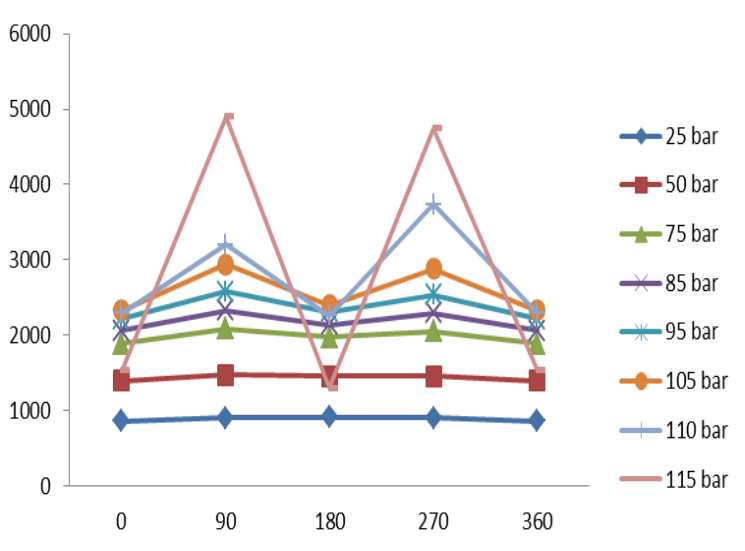

Angle around cylinder (degree)

Fig. 7: Circumferential strains for $10 \mathrm{~mm}$ thick vessels

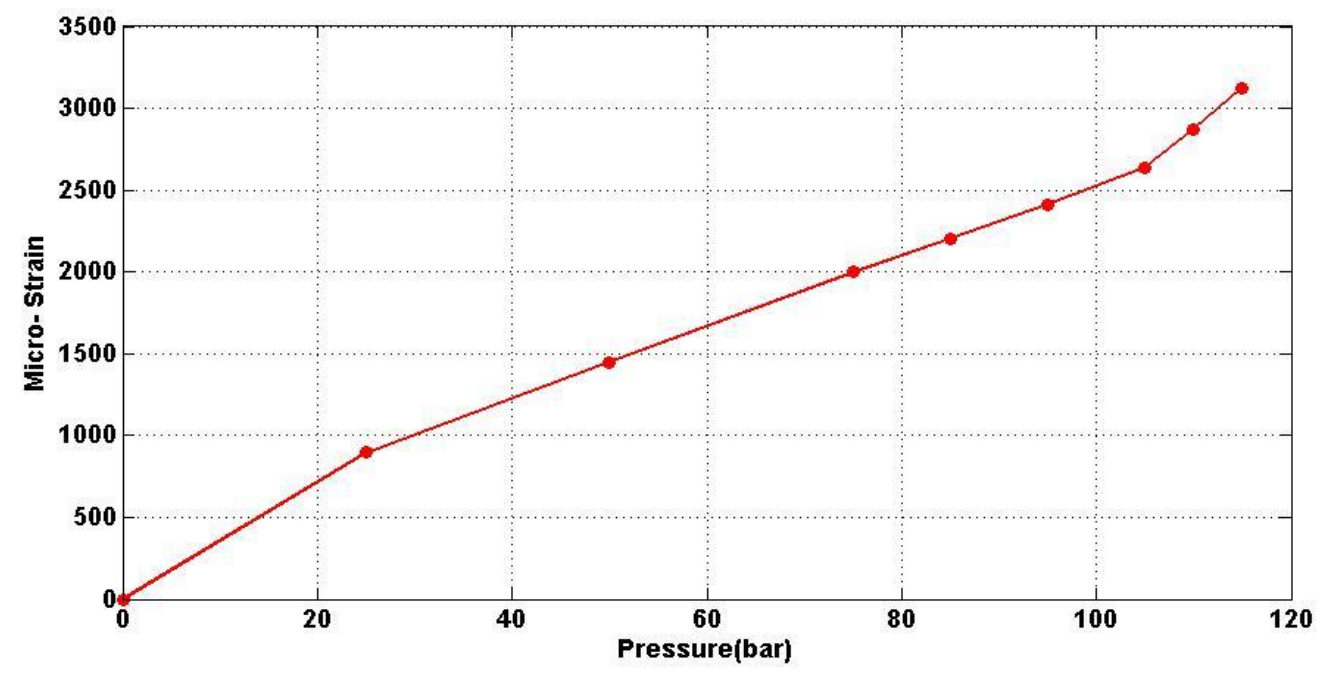

Fig. 8: Average circumferential strains for $10 \mathrm{~mm}$ thick shell vs. hydrostatic pressure 

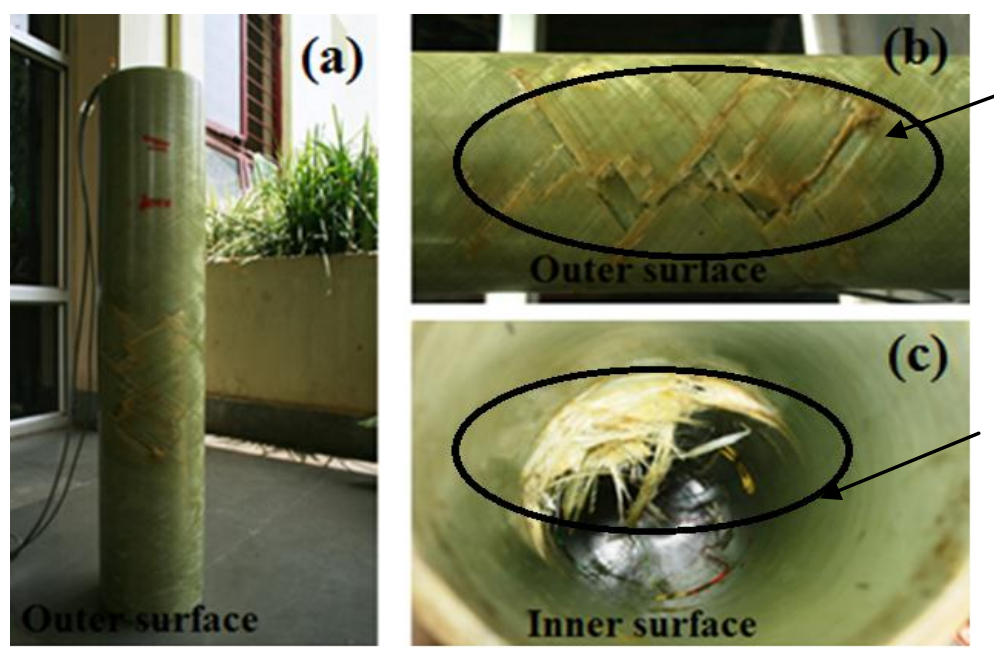

Buckled

Exploded view

Fig. 9: Cylinder a) tested for buckling, b) Buckled cylinder and c) Exploded view of the buckled portion

Table 2: Strain responses for $15 \mathrm{~mm}$ thick cylinder during Loading

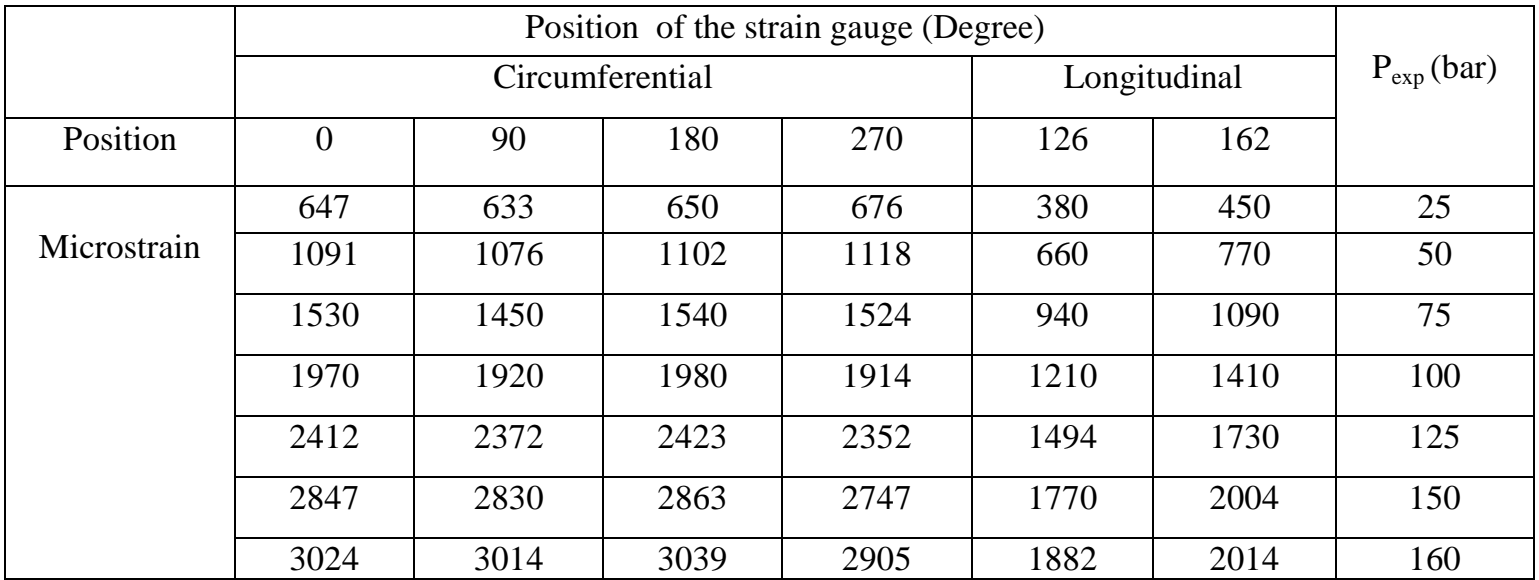

Typical circumferential strain plots are shown in Fig. 10 and 11, As the external pressure increased, the magnitudes of the circumferential strains grew with increasing external pressure, eventually making a distinct wave pattern. Average circumferential strain versus applied pressure is shown in Fig. 12, which showed that strains in both forward and reverse directions of loading were almost same indicating that the gauges were stable and the cylinder was still in the elastic region. Fig. 13 shows consistency in the strain gauge readings.

Table 3: Strain responses for $15 \mathrm{~mm}$ thick cylinder (Unloading)

\begin{tabular}{|c|c|c|c|c|c|c|c|}
\hline \multirow[b]{3}{*}{ Position } & \multicolumn{6}{|c|}{ Position of the strain gauge (Degree) } & \multirow{3}{*}{$\mathrm{P}_{\mathrm{exp}}(\mathrm{bar})$} \\
\hline & \multicolumn{4}{|c|}{ Circumferential } & \multicolumn{2}{|c|}{ Longitudinal } & \\
\hline & 0 & 90 & 180 & 270 & 126 & 162 & \\
\hline \multirow{7}{*}{ Microstrains } & 605 & 471 & 506 & 640 & 366 & 435 & 25 \\
\hline & 1050 & 993 & 1064 & 1066 & 648 & 742 & 50 \\
\hline & 1418 & 1441 & 1391 & 1444 & 929 & 995 & 75 \\
\hline & 1818 & 1856 & 1795 & 1815 & 1119 & 1369 & 100 \\
\hline & 2208 & 2285 & 2286 & 2265 & 1398 & 1699 & 125 \\
\hline & 2618 & 2721 & 2673 & 2632 & 1658 & 1984 & 150 \\
\hline & 2815 & 2945 & 2986 & 2857 & 1789 & 2005 & 160 \\
\hline
\end{tabular}




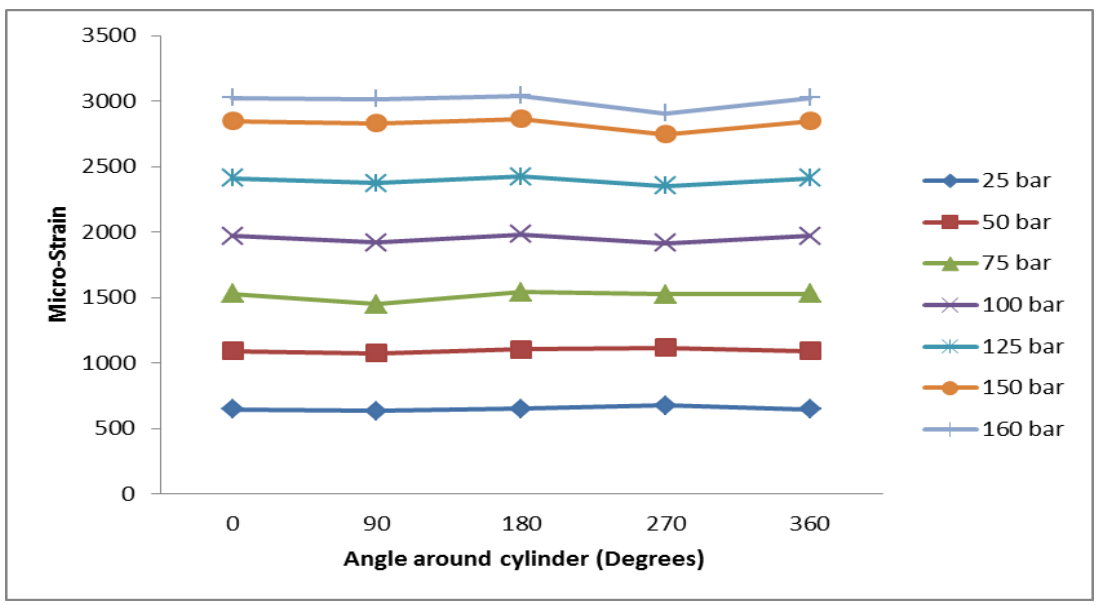

Fig. 10: Circumferential strains vs. Hydrostatic pressures for $15 \mathrm{~mm}$ thick vessel (Loading)

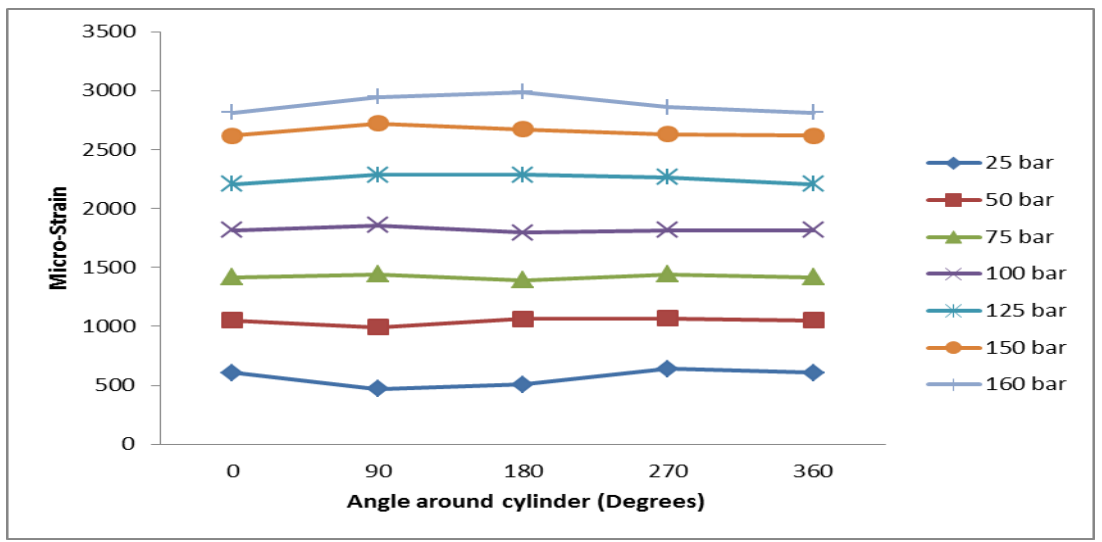

Fig. 11: Circumferential strains vs. pressures for $15 \mathrm{~mm}$ thick vessel (Unloading)

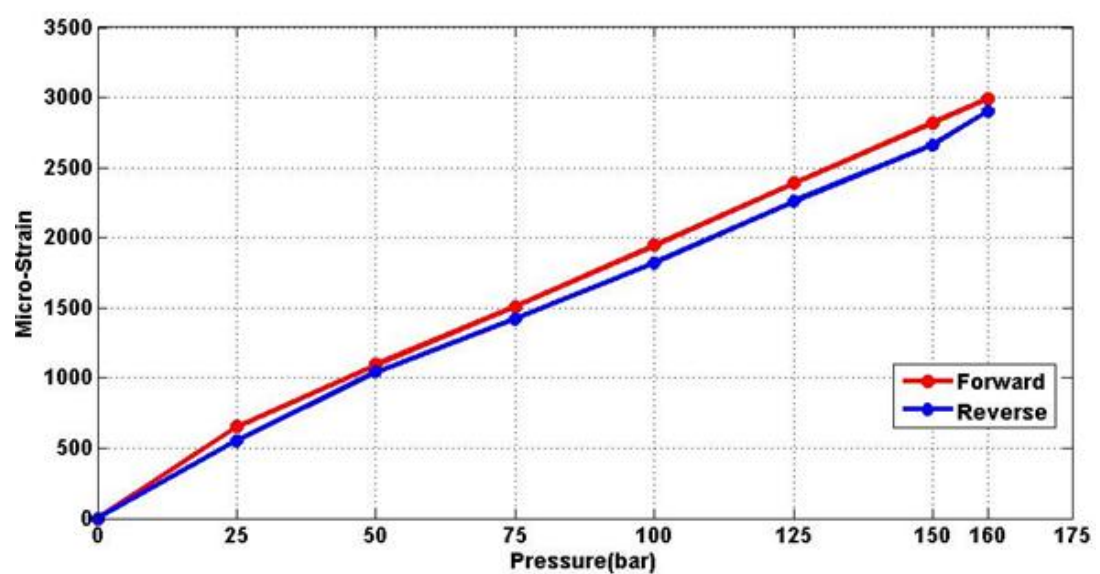

Fig. 12: Average circumferential strains for $15 \mathrm{~mm}$ thick vessel versus pressure (Loading and unloading) 


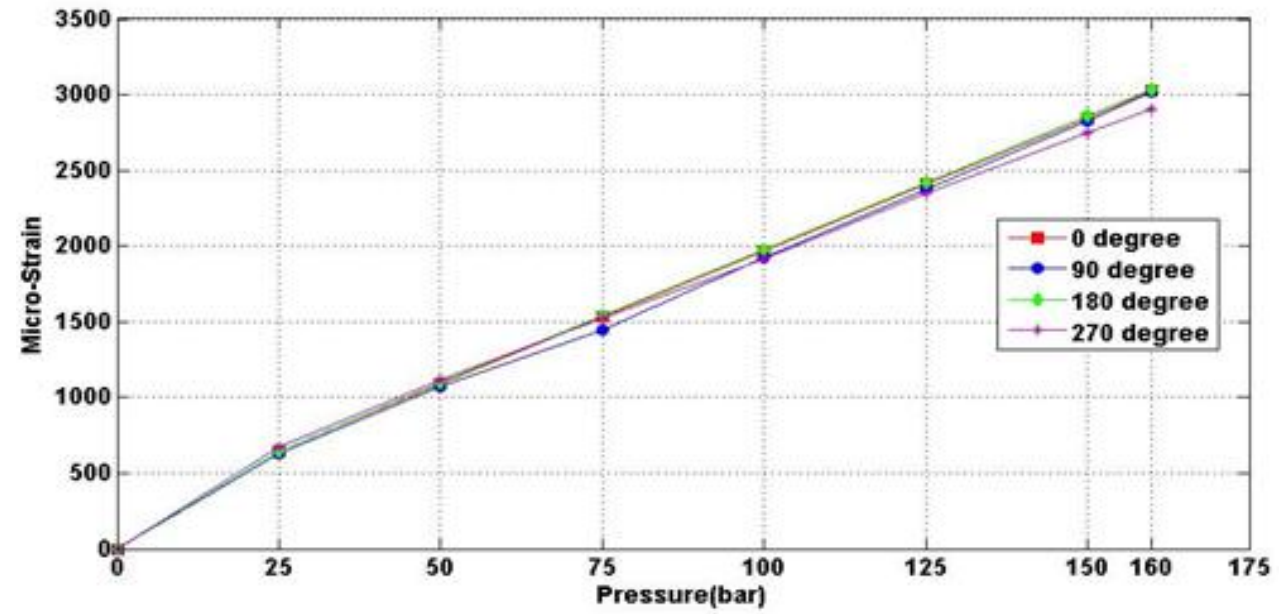

Fig. 13: Circumferential strains vs. Pressure for $15 \mathrm{~mm}$ thick vessel

\section{Finite Element Analysis for Buckling}

The orthotropic material properties of glass/vinylester composites considered for the Finite Element Analysis using ANSYS 10 are shown in Table 4. In order to define the material properties of the laminate, effective properties of stacking ply were introduced based on classical laminate theory. Additional assumptions such as: i) macroscopically each ply is homogeneous, linear-elastic and orthotropic, and ii) resin matrix is homogeneous, linear elastic and isotropic were considered.

Table 4: Orthotropic material properties considered for the present study, Massager et al. (2002)

\begin{tabular}{|c|c|c|c|c|c|c|c|c|}
\hline $\mathrm{E}_{1}, \mathrm{GPa}$ & $\mathrm{E}_{2, \mathrm{GPa}}$ & $\mathrm{E}_{3}, \mathrm{GPa}$ & $\mu_{12}$ & $\mu_{23}$ & $\mu_{13}$ & $\mathrm{G}_{12}, \mathrm{GPa}$ & $\mathrm{G}_{23}, \mathrm{GPa}$ & $\mathrm{G}_{13}, \mathrm{GPa}$ \\
\hline 45.5 & 16.1 & 16.1 & 0.28 & 0.28 & 0.39 & 5.84 & 5.84 & 5.77 \\
\hline
\end{tabular}

Meshing was accomplished in ANSYS using free mesh by employing linear layered structural shell elements Quad shell 99, which allowed up to 250 different material layers with different orientations and orthotropic material properties in each of the layers. It has six degrees of freedom at each node. Quality parameters such as warpage, aspect ratio, skew angle, Jacobian, minimum and maximum angles were satisfied while meshing. The meshed model is shown in Fig. 14.

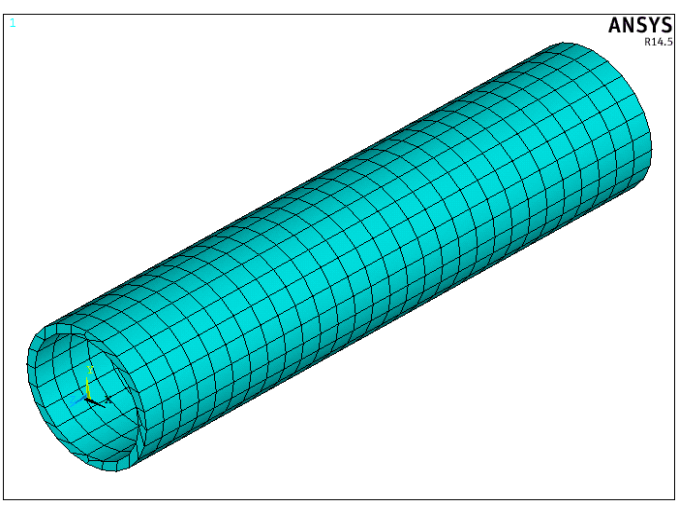

Fig. 14: Meshed model of cylindrical vessel

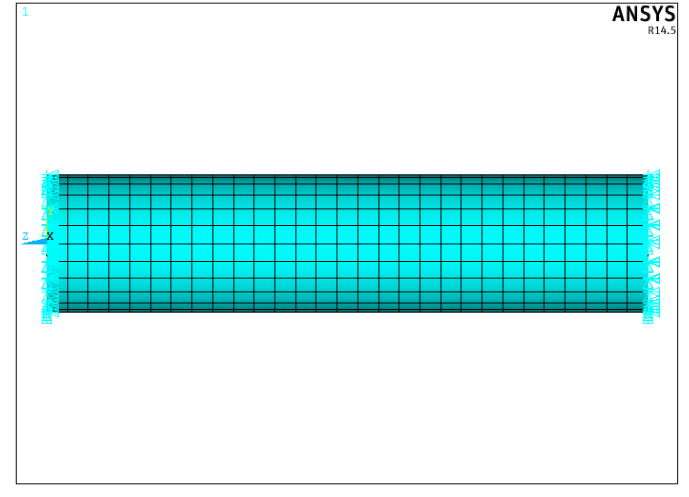

Fig.15: Meshed model with boundary conditions

The front end flange was assumed as fixed support and cap in the rear end was allowed to move in the axial direction. Thereby, the applied boundary condition in FEA was similar to that employed in the experimental studies as shown in Fig. 15. Uniform pressure of $1 \mathrm{MPa}$ was applied on the external surface normal to the shell elements as shown in Fig.16 and pressure was gradually increased to obtain the buckling modes.

Linear buckling was performed in two steps. In the first step, a static solution of the structure was obtained. In the static analysis prebuckling stress of the structure was computed. The second step involved solving the 
eigenvalue problem to obtain the eigenvalue by Block Lancos method as given by Equation (1) which takes into account the prebuckling stress stiffness matrix [S] computed in the first step.

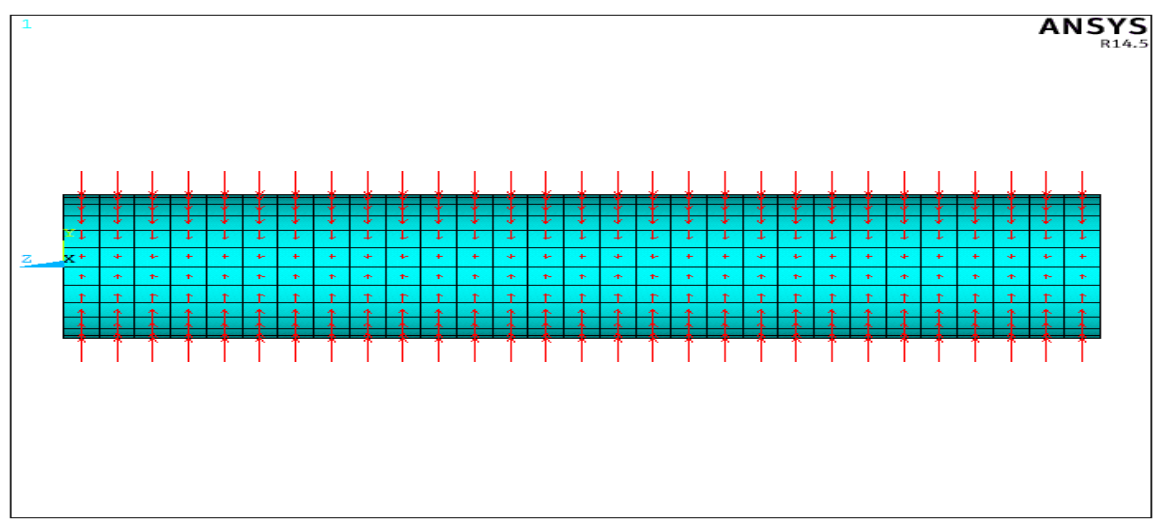

Fig.16: Meshed model with uniform external pressure

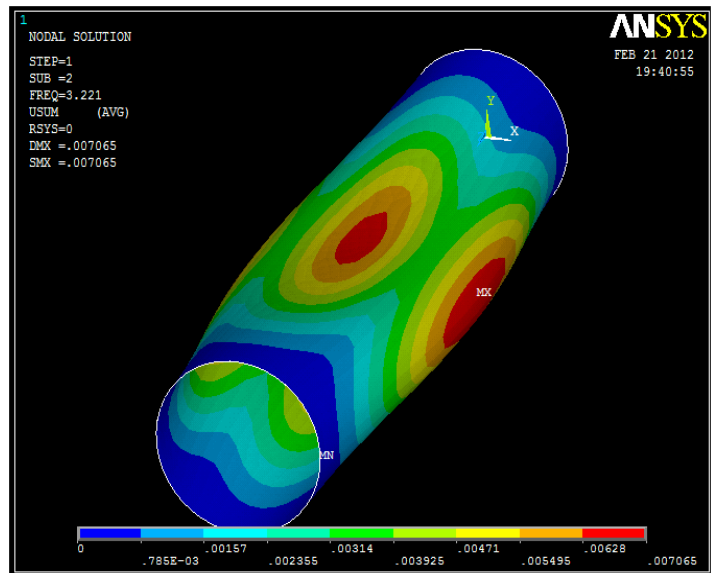

Fig. 17: Buckling of $10 \mathrm{~mm}$ thick vessel

$$
\begin{aligned}
\mathrm{CBP} & =\text { Frequency X Applied pressure } \\
& =5.169 \text { X } 2.5=12.92 \mathrm{MPa}
\end{aligned}
$$

$$
\left([\mathrm{K}]+\lambda_{\mathrm{i}}[\mathrm{S}]\right)\{\psi\}_{\mathrm{i}}=\{0\}
$$

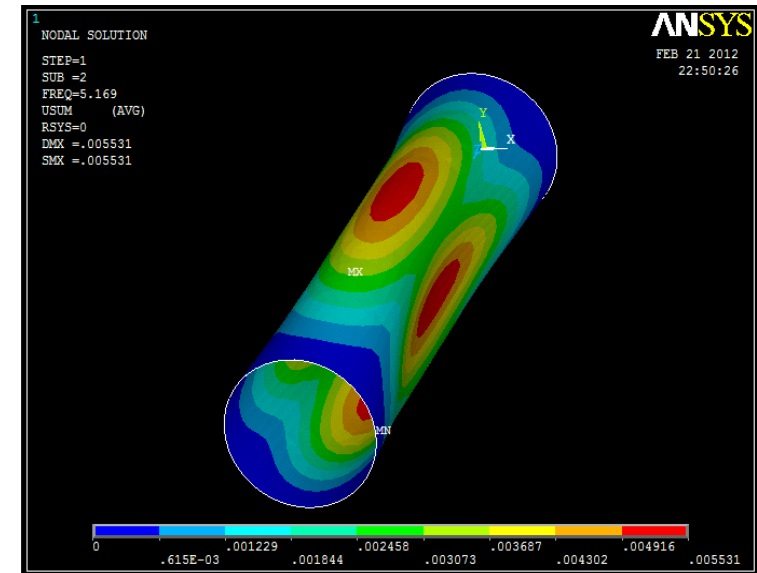

Fig. 18: Buckling of $15 \mathrm{~mm}$ thick vessel

$$
\begin{aligned}
\mathrm{CBP} & =\text { Frequency } \mathrm{X} \text { Applied pressure } \\
& =13.639 \mathrm{X} 2.5=34.09 \mathrm{MPa}
\end{aligned}
$$

where $[\mathrm{K}]=$ stiffness matrix, $[\mathrm{S}]=$ stress stiffness matrix, $\lambda_{\mathrm{i}}=\mathrm{i}^{\text {th }}$ eigenvalue (used to multiply the loads which generated $[\mathrm{S}])$ and $\psi_{\mathrm{i}}=\mathrm{i}^{\text {th }}$ eigenvector of displacements.

Once the eigenvalues are obtained, Critical buckling pressure $\left(\mathrm{P}_{\mathrm{cr}}\right)$ was obtained using Equation (2):

$$
\mathrm{P}_{\mathrm{cr}}=\lambda * \mathrm{P}_{\mathrm{a}}
$$

where $\mathrm{P}_{\mathrm{cr}}$ is the critical buckling pressure and $\mathrm{P}_{\mathrm{a}}$ is the applied pressure.

\subsection{Results of FEA}

Eigenvalues corresponding to buckling modes were obtained from ANSYS output file and Critical buckling pressure was calculated for $10 \mathrm{~mm}$ and $15 \mathrm{~mm}$ thickness by multiplying the obtained eigenvalue with the applied external pressure. Fig. 17 and 18 show $10 \mathrm{~mm}$ and $15 \mathrm{~mm}$ thick vessels respectively after buckling.

\section{Stress Analysis of Composite Shells}

Structural optimization of underwater vehicles is the subject of recent research. Sakthivel et al. (2011) simulated flow over underwater axisymmetric bodies at higher angles of attack. Gomatham et al. (2012) reported a nonlinear turbulence model to simulate flow past an autonomous underwater vehicle by considering them as axisymmetric bodies. Composite materials employed for axisymmetric underwater vessels (Fig. 19) are likely to satisfy the conditions of orthotropic elasticity. The cylindrical shells fall under the orthotropic material category. 
Cylindrical shells are generally considered as axisymmetric models since the variations in the angular direction are neglected. Karim et al. (2008) Studied underwater vehicle for viscous drag by considering them as axisymmetric bodies. Since the shells do not contain any out-of-plane loads, plane stress condition can be assumed for the cylinder.

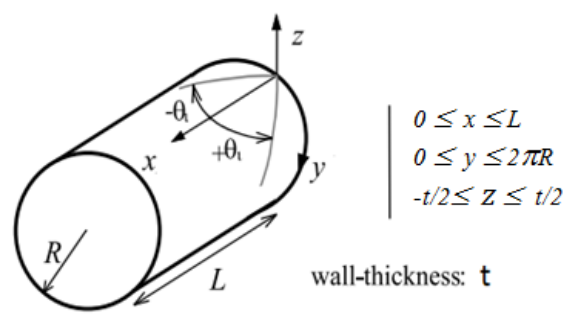

Fig. 19: Geometry of axisymmetric underwater vessel

The stress-strain relationship is given by Equation (3):

$$
\left(\begin{array}{l}
\sigma_{1} \\
\sigma_{2} \\
\tau_{12}
\end{array}\right)=\left(\begin{array}{ccc}
Q_{11} & Q_{12} & 0 \\
Q_{21} & Q_{22} & 0 \\
0 & 0 & Q_{66}
\end{array}\right)\left(\begin{array}{l}
\varepsilon_{1} \\
\varepsilon_{2} \\
\gamma_{12}
\end{array}\right)
$$

Where, $Q_{i j}$ is the reduced stiffness coefficient, $E_{1}, E_{2}, E_{3}$ are elastic moduli in direction 1, 2 and 3 corresponding to $\mathrm{x}, \mathrm{y}$ and $\mathrm{z}$ respectively, $\mu_{12}, \mu_{23}, \mu_{31}$ are Poisson's ratios, $\mathrm{G}_{12}, \mathrm{G}_{23}, \mathrm{G}_{31}$ are shear moduli in plane 12,23 and 31.

The stiffness coefficient is related to the engineering constants through Equations (4) to (7):

$$
\begin{aligned}
& \mathrm{Q}_{11}=\frac{E_{1}}{1-\mu_{21} \mu_{12}} \\
& \mathrm{Q}_{12}=\frac{\mu_{12} E_{2}}{1-\mu_{n 1} \mu_{12}} \\
& \mathrm{Q}_{22}=\frac{E_{2}}{1-\mu_{21} \mu_{12}} \\
& \mathrm{Q}_{66}=\mathrm{G}_{12}
\end{aligned}
$$

\begin{tabular}{|c|c|c|c|c|c|c|c|c|}
\hline \multirow[t]{2}{*}{ Thickness } & \multirow{2}{*}{$\begin{array}{l}\mathrm{Q}_{11} \\
\mathrm{GPa}\end{array}$} & \multirow{2}{*}{$\begin{array}{l}\mathrm{Q}_{12} \\
\mathrm{GPa}\end{array}$} & \multirow{2}{*}{$\begin{array}{l}\mathrm{Q}_{22} \\
\mathrm{GPa}\end{array}$} & \multirow{2}{*}{$\begin{array}{l}\mathrm{Q}_{66} \\
\mathrm{GPa}\end{array}$} & \multirow{2}{*}{$\begin{array}{l}\text { Pressure } \\
\mathrm{MPa}\end{array}$} & \multicolumn{2}{|c|}{ Principal stresses } & \multirow{2}{*}{$\begin{array}{l}\text { Von-Mises } \\
\text { stresses } \\
\sigma_{\mathrm{ys}} \mathrm{MPa} \\
\end{array}$} \\
\hline & & & & & & $\sigma_{1} \mathrm{MPa}$ & $\sigma_{2} \mathrm{MPa}$ & \\
\hline \multirow{8}{*}{$10 \mathrm{~mm}$} & \multirow{8}{*}{49.4} & \multirow{8}{*}{4.88} & \multirow{8}{*}{17.55} & \multirow{8}{*}{5.83} & 2.5 & 46.69 & 10.7 & 42.36 \\
\hline & & & & & 5 & 77.01 & 22.11 & 68.68 \\
\hline & & & & & 7.5 & 109.85 & 33.97 & 97.41 \\
\hline & & & & & 8.5 & 122.66 & 38.57 & 108.65 \\
\hline & & & & & 9.5 & 135.99 & 43.30 & 120.3 \\
\hline & & & & & 10.5 & 155.04 & 49.62 & 137.13 \\
\hline & & & & & 11 & 123.98 & 49.54 & 108.08 \\
\hline & & & & & 11.5 & 87.49 & 49.26 & 75.96 \\
\hline \multirow{7}{*}{$15 \mathrm{~mm}$} & \multirow{7}{*}{49.4} & \multirow{7}{*}{4.88} & \multirow{7}{*}{17.55} & \multirow{7}{*}{5.83} & 2.5 & 35.586 & 11.18 & 31.51 \\
\hline & & & & & 5 & 58.987 & 18.96 & 52.15 \\
\hline & & & & & 7.5 & 81.39 & 26.64 & 71.87 \\
\hline & & & & & 10 & 104.69 & 34.40 & 92.42 \\
\hline & & & & & 12.5 & 128.13 & 42.18 & 113.10 \\
\hline & & & & & 15 & 145.48 & 48.57 & 128.28 \\
\hline & & & & & 16 & 159.95 & 50.17 & 141.69 \\
\hline
\end{tabular}

For the plane stress condition $\sigma_{3}=0, \tau_{23}=0$ and $\tau_{31}=0$. Orthotropic properties shown in Table (4) are used in Equations (4) through (7) to calculate the values of stiffness coefficient $\mathrm{Q}_{\mathrm{ij}}$.

Table 5 Von-Mises Stresses for $10 \mathrm{~mm}$ and $15 \mathrm{~mm}$ thick composite shells 
By substituting the values of circumferential and longitudinal strains obtained from the experimental results along with the stiffness coefficients $\mathrm{Q}_{\mathrm{ij}}$ obtained from Equations (4) to (7) in Equation (3), principle stresses $\sigma_{1}$ and $\sigma_{2}$ are obtained. In plane stress condition $\sigma_{3}$ is zero.

Now, consider Equation (8)

$$
2 \sigma_{\mathrm{ys}}{ }^{2}=\left(\sigma_{1}-\sigma_{2}\right)^{2}+\left(\sigma_{2}-\sigma_{3}\right)^{2}+\left(\sigma_{3}-\sigma_{1}\right)^{2}
$$

By substituting the values of principal stresses $\sigma_{1}$ and $\sigma_{2}$ in Equation (8) Von-Mises stresses as obtained are presented in Table 5. For $10 \mathrm{~mm}$ thick shell as pressure increased from 2.5 to $11 \mathrm{MPa}$, the Von-Mises stresses increased by $155 \%$. At $11.5 \mathrm{MPa}$ applied pressure there was sudden drop of $29 \%$ in Von-Mises stresses as the vessel buckled at this pressure, Fig. 20 a) For $15 \mathrm{~mm}$ thick shell as the pressure increased from 2.5 to $16 \mathrm{MPa}$, the Von-Mises stresses increased by $349 \%$ and the shell was found be in the elastic limit as observed from Fig. $20 \mathrm{~b})$.
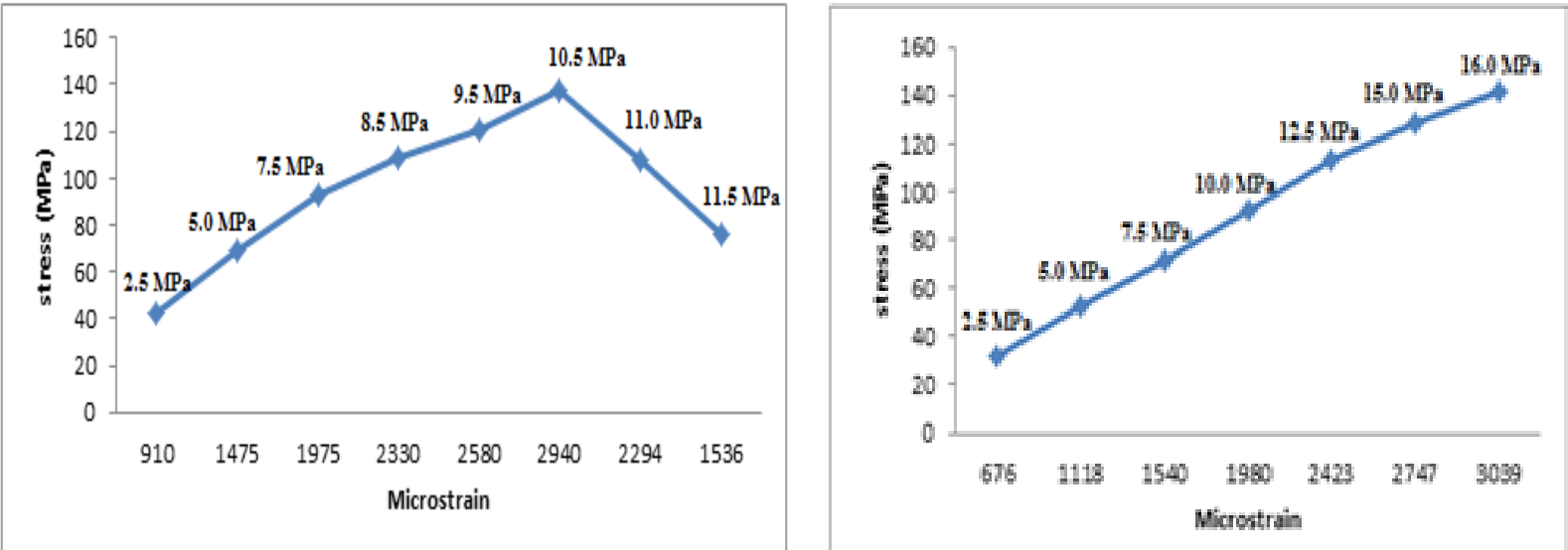

Fig. 20: Von Mises Stresses v/s microstrains for a) $10 \mathrm{~mm}$ thick shell and b) $15 \mathrm{~mm}$ thick shell

\section{Validation of Results}

\subsection{Validation of experimental and FEA strains}

Critical buckling pressure predicted by FEA for $10 \mathrm{~mm}$ thick shell was $12.92 \mathrm{MPa}$ whereas the experimental CBP was $12.0 \mathrm{MPa}$, which means a deviation of $7.12 \%$ deviation from that of the experimental results because of the imposed boundary conditions, possibility of multiple configurations of the shell to deform around the buckling load and not accounting for initial imperfections in the shell in the Finite Element Analysis. Similar deviations are reported by Hur et al (2008).

Table 6 and 7 show the strains as a function of hydrostatic pressure obtained experimentally and by FEA for 10 $\mathrm{mm}$ and $15 \mathrm{~mm}$ thick shells respectively. The strains obtained from FEA results for $10 \mathrm{~mm}$ and $15 \mathrm{~mm}$ thick vessels were predicted with $1.71 \%$ to $32.9 \%$ and $0.96 \%$ to $13.28 \%$ deviations from the experimental strains respectively, as shown in Table 6 and Table 7. The deviation was because experimental and FE buckling modes do not coincide with each other. Figs. 21 and 22 show good agreement of FEA strains with that of experimental strains except at a pressure of 115 bar for $10 \mathrm{~mm}$ thick vessel because during the experiment strains changed suddenly around the critical buckling pressure of 120 bar, but in FEA due to static analysis the cylinder does not fail at any pressure.

Table 6: Comparison of Experimental strains with FEA strains for $10 \mathrm{~mm}$ thick vessel

\begin{tabular}{|c|c|c|c|}
\hline Pressure (bar) & Experimental microstrain & FEA microstrain & Deviation \\
\hline 25 & 906 & 715 & $21.08 \%$ \\
\hline 50 & 1475 & 1429 & $3.22 \%$ \\
\hline 75 & 2090 & 2144 & $2.42 \%$ \\
\hline 85 & 2330 & 2430 & $4.11 \%$ \\
\hline 95 & 2580 & 2716 & $5.00 \%$ \\
\hline 105 & 2940 & 3002 & $2.06 \%$ \\
\hline 110 & 3200 & 3145 & $1.71 \%$ \\
\hline 115 & 4900 & 3287 & $32.9 \%$ \\
\hline
\end{tabular}


Table 7: Comparison of experimental strains with FEA strains for $15 \mathrm{~mm}$ thick shell

\begin{tabular}{|c|c|c|c|}
\hline Pressure (bar) & $\begin{array}{c}\text { Experimental } \\
\text { microstrain }\end{array}$ & FEA microstrain & Deviation \\
\hline 25 & 633 & 585 & $7.58 \%$ \\
\hline 50 & 1076 & 933 & $13.28 \%$ \\
\hline 75 & 1450 & 1399 & $3.51 \%$ \\
\hline 100 & 1920 & 1866 & $2.81 \%$ \\
\hline 125 & 2372 & 2332 & $1.68 \%$ \\
\hline 150 & 2830 & 2799 & $1.09 \%$ \\
\hline 160 & 3014 & 2985 & $0.96 \%$ \\
\hline
\end{tabular}

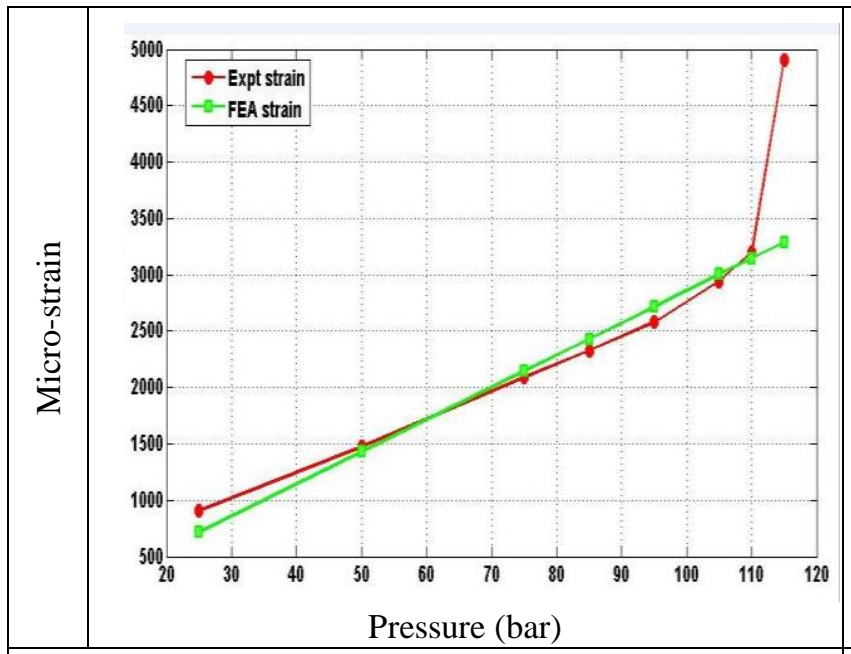

Fig. 21: Experimental and FEA Strains vs. applied pressure for $10 \mathrm{~mm}$ thick shell

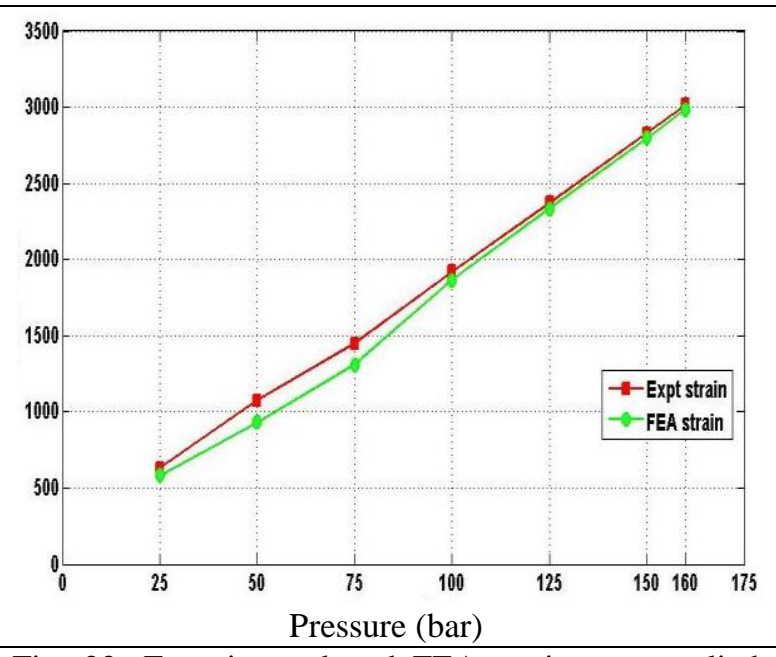

Fig. 22: Experimental and FEA strains vs. applied pressure for $15 \mathrm{~mm}$ thick vessel

\subsection{Validation of analytical and FEA stresses}

Table 8 and 9 show the Von-Mises stresses as a function of applied pressure obtained analytically and by FEA for $10 \mathrm{~mm}$ and $15 \mathrm{~mm}$ thick shells respectively. The range of deviations between the stresses predicted by FEA and analytical approaches were 7.2 to $14.4 \%$ for $10 \mathrm{~mm}$ thick shells. The corresponding values for $15 \mathrm{~mm}$ thick shells were 1.15 to $24.85 \%$. The analytical stresses were derived from the experimental strain data using reduced stiffness matrix. Experimental and FEA results cannot be directly compared because the buckling modes do not coincide with each other. Fig. 23 and 24 show the stress for $10 \mathrm{~mm}$ and $15 \mathrm{~mm}$ thick vessel respectively.

Table 8: Comparison of analytical stresses with FEA stresses for $10 \mathrm{~mm}$ thick vessel

\begin{tabular}{|c|c|c|c|}
\hline Pressure (bar) & Analytical stresses $(\mathrm{MPa})$ & FEA stresses $(\mathrm{MPa})$ & Deviation \\
\hline 25 & 42.36 & 37.011 & $12.62 \%$ \\
\hline 50 & 68.68 & 74.023 & $7.2 \%$ \\
\hline 75 & 97.41 & 111.034 & $12.2 \%$ \\
\hline 85 & 108.65 & 125.838 & $13.6 \%$ \\
\hline 95 & 120.3 & 140.643 & $14.4 \%$ \\
\hline 105 & 137.13 & 155.447 & $11.78 \%$ \\
\hline
\end{tabular}


Table 9: Comparison of analytical stresses with FEA stresses for $15 \mathrm{~mm}$ thick vessel

\begin{tabular}{|c|c|c|c|}
\hline Pressure (bar) & Analytical stresses (MPa) & FEA stresses (MPa) & Deviation \\
\hline 25 & 31.51 & 23.679 & $24.85 \%$ \\
\hline 50 & 52.15 & 47.358 & $9.18 \%$ \\
\hline 75 & 71.87 & 71.037 & $1.15 \%$ \\
\hline 100 & 92.42 & 94.716 & $2.42 \%$ \\
\hline 125 & 113.10 & 118.395 & $4.47 \%$ \\
\hline 150 & 128.28 & 142.074 & $9.7 \%$ \\
\hline 160 & 141.69 & 151.546 & $6.5 \%$ \\
\hline
\end{tabular}

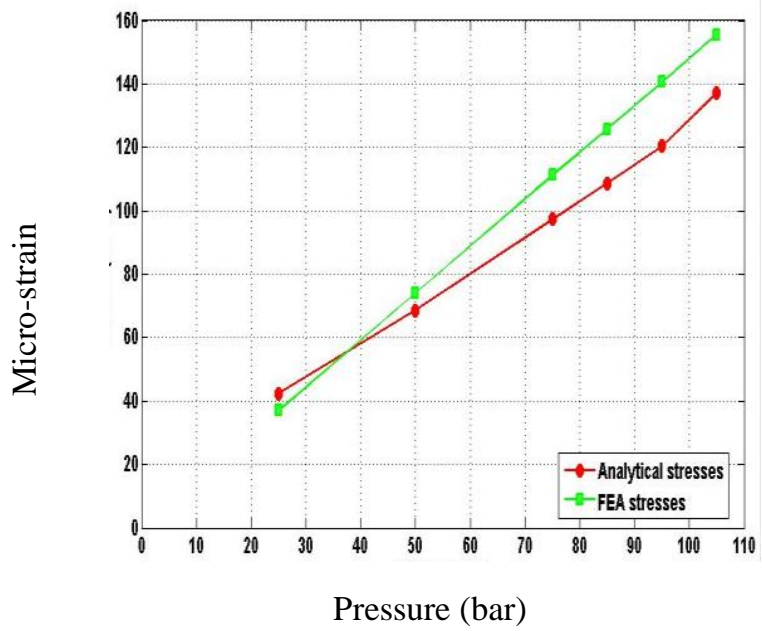

Fig. 23: Analytical and FEA stresses vs. applied pressures for $10 \mathrm{~mm}$ thick vessel

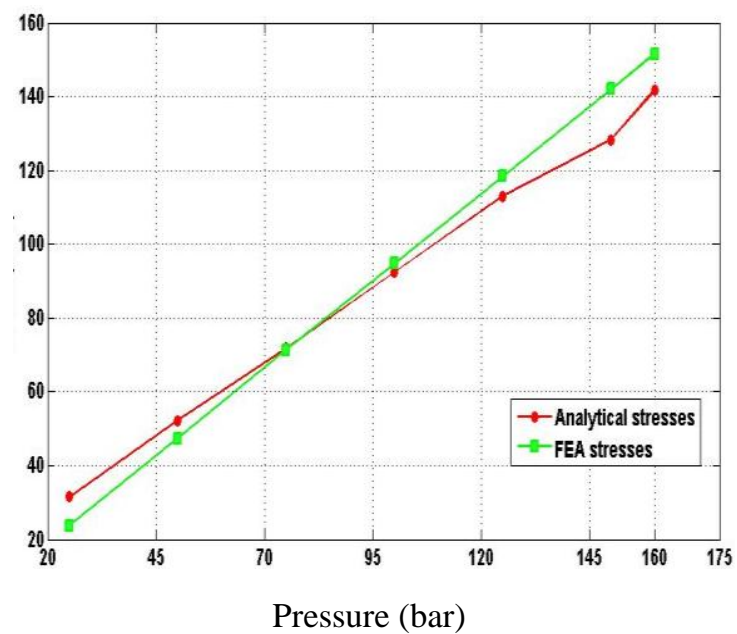

Fig. 24: Analytical and FEA stress vs. applied pressures for $15 \mathrm{~mm}$ thick vessel

\section{Conclusions}

Buckling behaviour of filament wound cylindrical shells was investigated by experimental, numerical and analytical approaches. Based on the results, the following conclusions were arrived at:

> Experimental critical buckling pressure of $10 \mathrm{~mm}$ thick shell of $825 \mathrm{~mm}$ length, $175 \mathrm{~mm}$ internal diameter, made of glass/vinylester was $12 \mathrm{MPa}$ whereas that predicted by FEA using was $12.92 \mathrm{MPa}$, showing good agreement with each other.

Strains as a function of varying hydrostatic pressure from 25 bar to 105 bar for the $10 \mathrm{~mm}$ thick shell were predicted by static buckling analysis of ANSYS with deviations ranging from $1.71 \%$ to $32.9 \%$ from the experimental strains. Highest deviation of $32.9 \%$ occurred at 115 bar because at the onset of buckling, the strains increase significantly, which is predicted by the linear static buckling analysis of ANSYS.

$>$ Von-Mises stresses at different applied hydrostatic pressures were predicted using RSM based on experimental circumferential and longitudinal strains. Von-Mises stresses predicted by FEA and RSM closely agreed with a maximum deviation of $14.4 \%$ for $10 \mathrm{~mm}$ thick shell.

$>$ Strains as a function of hydrostatic pressure from 25 bar to 160 bar for $15 \mathrm{~mm}$ thick, $175 \mathrm{~mm}$ internal diameter and $825 \mathrm{~mm}$ long shells were predicted by linear static buckling analysis of ANSYS with a maximum deviation of $13.28 \%$ from the experimental strains. These shells were not loaded to collapse pressure due to the limitations in the tester.

$>$ Von-Mises stresses as a function of applied pressure were obtained analytically and by FEA for the 15 $\mathrm{mm}$ thick shells with maximum deviations in the range of $1.15 \%$ to $24.85 \%$. These stresses are derived from the experimental strain data. 


\section{Acknowledgements}

The authors are grateful to NRB, New Delhi and NPOL, Kochi for the financial support for this research work

\section{References}

Carvelli, V., Panzeri, N., and Poggi, C. (2001): Buckling strength of GFRP under-water vehicles, Composite Part B, Vol. 32, No. 2, pp. 89-101.

Gomatam, S., Vengadesan, S., and Bhattacharyya, S.K. (2012): Numerical simulations of flow past an autonomous underwater vehicle at various drift angles, Journal of Naval Architecture and Marine Engineering Vol. 9, No.2, pp. 135-152. http://dx.doi.org/10.3329/jname.v9i2.12567

Graham, D. (1995): Composite Pressure Hulls for deep ocean submersibles, Composite structure, Vol 32. pp. 331-343.

Hahn, H.T., Jensen, D.W., Claus, S.J., Pai, S.P., and Hipp, P.A. (1994): Structural design criteria for filamentwound composite shells, NASA CR195125.

Moreno, H., Douchin, B., Collombet, F., Choqueuse, D., and Davies, P. (2008): Influence of winding pattern on the mechanical behavior of filament wound composite cylinders under external pressure. Composite Science Technology, Vol 68. No (3-4). pp. 1015-1024. http://dx.doi.org/10.1016/j.compscitech.2007.07.020

Joung, T.H., Lee, C. M., Hong, S. W., Kim, J. B., and An, C. W. (2004): A study on the results of the pressure vessel design. Structural analysis and pressure test of the semiautonomous underwater vehicle (SAUV), Korean Society of Ocean Engineering, Vol. 18 pp. 52-58.

Karim, M. M., Rahman, M. M., and Alim, M. A. (2008): Numerical computation of viscous drag for axisymmetric underwater vehicles, Jurnal Mekanical, No.26, pp. 9-21.

Ng, R. K. H., Yousefpour, A., Uyema, M., and Nejhad, M. N. G. (2002): Design, analysis, manufacture, and test of shallow water pressure vessels using e-glass/epoxy woven composite material for a semi-autonomous underwater vehicle, Journal of Composite Material Vol.36. No.21, pp. 2443-2478.

Ross, C. T. F. (2006): A conceptual design of an underwater vehicle. Ocean Engineering, Vol. 33, pp. 20872104.

Ross, C. T. F., Okoto, K. O., and Little, A. P. F. (2008): Buckling by general instability of cylindrical components of deep sea submersible, Applied Mechanics and Materials, Vol. 13-14, pp. 289-296. http://dx.doi.org/10.4028/www.scientific.net/amm.13-14.289

Sathivel, R., Vengadesan, S., and Bhattacharyya, S.K. (2011): Application of non-linear $k$ - $\varepsilon$ turbulence model in flow simulation over underwater axisymmetric hull at higher angle of attack, Journal of Naval Architecture and Marine Engineering, Vol. 2, pp. 149-163. http://dx.doi.org/10.3329/jname.v8i2.6984.

Hur, S. H., Son, H. J., Kweon, J. H. and Choi. J. H. (2008): Post buckling of composite cylinders under external hydrostatic pressure, Composite Structure, Vol. 86, pp. 114-124. http://dx.doi.org/10.1016/j.compstruct.2008.03.028

Smith C. S. (1991): Design of submersible pressure hulls in composite materials. Marine Structure, Vol. 4, pp. $141-182$.

Messager, T., Pyrz, M., Gineste, B. and Chauchot. P. (2002): Optimal laminations of thin underwater composite cylindrical vessels, Journal of Composite Structures, Vol. 58, pp. 529-537.

Messanger, T. (2001): Buckling of imperfect laminated cylinders under hydrostatic pressure, Composite Structures. Vol. 53, pp. 301-307 